SEROQUEL is indicated for the treatment of schizoohrenia.
The efticacy of SEROQUEL in schizophrenia was established in short-term (6-
weeki controlled trials of schizophrenic inpatients (See CLINICAL PHARMACOLOGY)

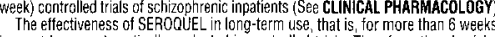
The effectiveness of SEROQUEL in long-term use, that is, tor more than 6 weeks,
has not been systematically eval uated in controlled trials. Therefore, the physician the Iong-term usefulness of the drug tor the individual patient.
CONTRAINDICATIONS

fication or any of its ingrededients.

Neuroleptic Malignant Syndrome: (NMS) A potentially fatal symptom complex
(a) in association with administration of antipsychotic drugs. Iwo possible cases of
NMIS $521238370.1 \%$. 19 have been reported in clinical trials with SERODUEL. Clinical manifiestations of NMS are hyperpysexia, muscle rigidily, altered mental status, anc
evicence of autonomic instability (irregullar pulse or blood pressure, tachycardia

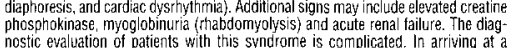
nostic evaluation of patients with this syndrome is complicated. In arryving at a
diagnosis it is important to exclude cases where the clinical presentation includes

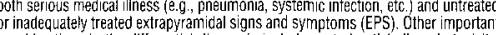

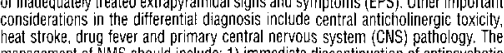

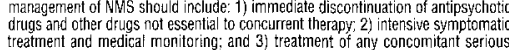
medical problems for which specific treatments are available. There is no general
agreement about specific pharmacological treatment reg mens for MMS. If a patient requires antipsychotic drug treatment after recovery from NMS. the potential reir-
troduction of drug therapy shoutkl be carefully considered. The patient should be carefululy monitored since recurrences of NMS have been reported. Tardive
Dyskinesia: $A$ syndrome of potentially irreversible, involuntary. dyskinetic moveDyskinesia: A syndrome of potentialy irreversible, involuntary. dyskinetic, move
ments may develop in patients treated with antipsychotic orugs. Athough the
prevalence of the syndrome appears to be highest among the elderly. especially eiderly women it is is impossible to rely upon prevalence estimates to predict, at the inception of antipsychotic treatrrent. which patients are tikely to develop the syn-
drome. Whether antipsychotic drug products difter in their potential to cause tardive
dyskinesia is unknown. The risk of developing tardive dyskinesia and the like ihrood that it will become rreversible are believed to increase as the duration of treatment
and the total cumulative dose of antipsychotic drugs administered to the patient increase. However, the syndrome can devetop, although much less commonly, after
relatively brief treatment periods at low doses. There is no known treatment for

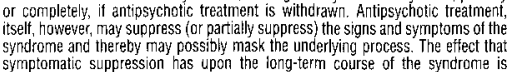

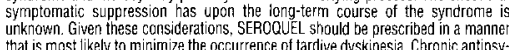

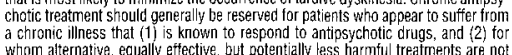

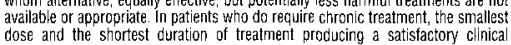
response should be sought. The need for continued treatment should be reassessed periodically. If signs and symptoms of tardive dyskinesia appear in a patient on may require treatment with
PRECAUTIONS: General

SEOLEL may induce orthostatic hypotension associated with dizziness, tachycardia and, in some patients, syncope, especially diring properties. Syncope was reported in $1 \%$ (22/2162) of the patients treated with
SEROOUEL, compared with $0 \%$ (0/206) on plasebo and about $0.5 \%$ (2/420) on active contral drugs. The risk of orthostatic hypotension and syncope may be
minimizec by fimiting the initial dose to $25 \mathrm{mg}$ bid. If hypotension occurs during

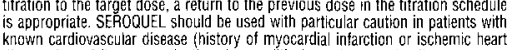

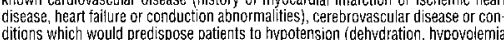

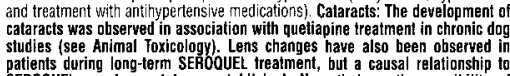

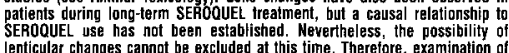
the lens by methods adequate to detect cataract formation, such as slit lame

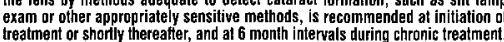
traatment or shortly thereatter, and at 6 month intervals during chronic treatmenti.
Seizures: During clinical trials, seizures occurred in $0.8 \%(18 / 2387)$ of patients treated with SEROOUEL compared to $0.5 \%$ (1/206) on placebo and $1 \%$ (4/420) on
active control drugs. AS with other antipsychotics SEROOUEL should be used cautiously in patients with a history of seizures or with conditions that potentially
lower the seizuse threshold, e.g., Azheirmer's dermentia. Conditions that lower the

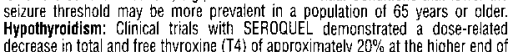

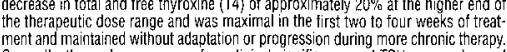
Generally, these changes were of no clinical significance and TSH was unchanced in most patients. and levets of TBG were unchanged. In nearly all cases, cessation
of SEROQUEL treatment was associated with a reversal of the effects on total and

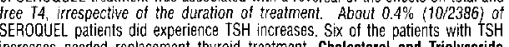
increases needed replacement thyroid treatment. Cholesterol and Triglycerida
Elevations. In a pool of 3- to 6 -week placebo-controlled trials, SERODUEL-treated patients had increasss from baseline in cholesterol and tiriglyceride of $11 \%$ and
$17 \%$, respectively, compared to slight decreases for placebo patients. These
changes were only weakly related to the increases in weight cbserved in SEROQUEL-

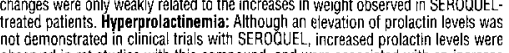

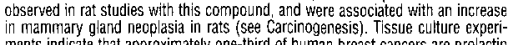
dependent in vitro a a factor of potential impoitance if the prescription of these drugs
is contemplated in a patient with previous y detected breast cancer. Although
disturbances such as galactorthea, amenorrhea, gynecomastia, and impotence have been reported with prolactir-elevating compounds, the clinical significance of
elevated serum prolactin levels is unknown for most patients. Nie ther clinical studies nor epidemiologic studies cond ucted to date have shown an association between chronic administration of this class of drugs and tumoricenesis in humans; the
avaiable evidence is considered to olimted to be conclusive at this time.
Transaminase Elevations: Asymptomatic, transient and revers ble elevations in Transaminase Elevations: Asymptomatic, transient and reversible elevations in
serum transaminases (primarily ALT) have been reported. The proporticns of
patients w'th transaminase elevations of $>3$ times the upper limits of the norma

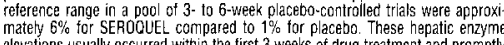
elevations usually occurred wittin the first 3 weeks of drug treatment and promptly
returned to pre-study levels with ongoing treatment with SEROQUEL. Potential tor

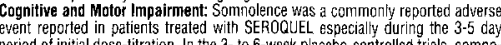
period of intital dose-titration. In the 3 - to 6 -wweek placeceb-controfled trials, somnopatients. Since SEROOUEL has the potential to impair judgment, thinking or motor alertress, such as operating a motor vehicle (including automobies) or operating
hazardsus machinery untili they are reasonably certaint thal I EROROULL L therapy

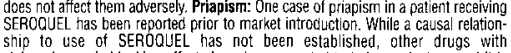
ship to use of SEROOUEL has not been established, other drugs with
alpha-adrenergic blocking effects have been reported to induce priapism, and it is
possibte that SEROOUL surgical interventicn. Body Temperature Regulation: Although not reported with
SERQouluL, disruption of the body's ab lity to reduce core body temperature has been attributed to antipsychotic agents. Appropriate care is advised when prescribing

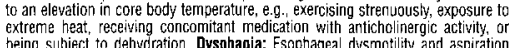

SEROQUEL (quetiapine fumarate) Tablets

have been associated with antipsychotic drug use. Aspiration pneumonia is a common
cause of morbidity and mortality in elderly patients. in particular those with advanced Azznemer's dementia. SEROQUEL and other ant psychotic drugs
should be used cautiously in patients at risk for aspiration pneumonia. Suicide: of high risk patients should accooinpany drug therapy. Prescriptions tor SEROQUEL
should be written for the smallest quantity of tablets consistent with onod patient management in order to reduce the risk of Overdose. Uise in Patients with
Concomitant Illness: Clinical experience with SEROOUEL in patients with certain Coneomitant Illness: Clinical experience with SEROQUEL in patients with certain
concomitant systemic illnesses is iimited. SEROQUEL has not been evaluated or tion or unstabie heart disease. Patients with these ciagnoses were excluded from
premerketing clinical studies. Because of the risk of orthostatic hypptension with SEROQUEL, caution should be observed in cardiac patients (see Orthostatic Hypotension). Information for Patients: Physicians are advisised to discuss the
following issues with patients for whom they prescribe SEROOUEL. Orthosiatic
Hypotension: Patients should be advised of the risk of orthostatic hypotension especialy during the $3-5$ day period of initial dose titration, and also at times of
re-initiating treatment or increases in dose. Interference wilh Cognitive and Motor Performance: Since somnolence was a commonly reported adverse event associated
with SEROOUUEL treatment, patients should be advised of the risk of sornnolence,
especialy during the 3-5 day period of initial dose titration Patients should be

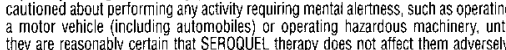

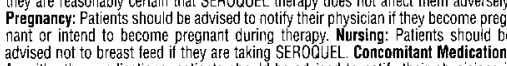

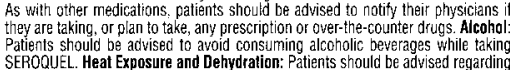
SEROQUEL. Heat Exposure and Dehydration: Patients stould be advised regarding SEROOUEL in combination with other drugs have not been extensively evaluated

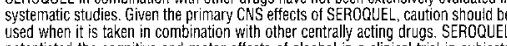
potentiated the cognitive and motor effects of alconol in a clinical trial in subjects
with selected syychotic disorders and alcoholic beverages should be avoided while

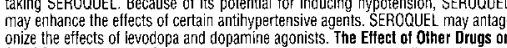

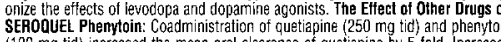
(1000 $\mathrm{mg}$ tid) increased the mean oral clearance of quetiapine by 5 -fold. Increased
doses of phreniz in patients receiving quetiapine and phenytoin, or other hepatic enzym
inducers ie.g., carbamazepine, barbiturates, rifampin, glucocorticoidst. Caution

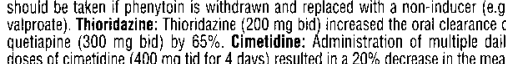

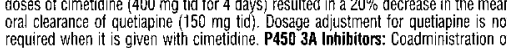
ketoconazole 200 mg once daily for 4 days), a aptent inhibitor of cytochrome P45
$3 A$ reduced oral clearance of quetiapine by $84 \%$, esulting in a $335 \%$ increase is administered with ketoconnazole and other inhibitors of cytochrome P450 3 A

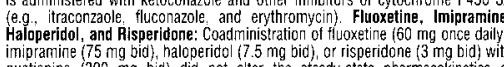

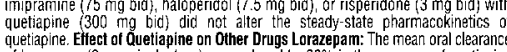
of torazeam (2 mg, single dose) was reduced by $20 \%$ in the preserce of quetiapin administered as $250 \mathrm{mg}$ tid dosing. Lithium: Concomitant administration

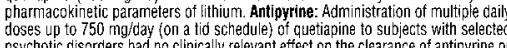
pSychotic disorcers had no clinically relevant effect on the clearance of antipyrine or
urinary recovery of antipyrine metaoolites. These results indicate that quetiaping does not significantly induce tepatic enzymes responsible for cytochrome P450
mediated metabolism of antipyrine. Carcinogenesis, Mutagenesis, Impairment Fertility Carcinotgenesis: Carcinogenicity studies were conducted in $\mathrm{CS}_{7} \mathrm{BL}$ mice
and Wistar rats. Quetasine was administered in the diet to mice at doses of 20,75 , 250 , and $750 \mathrm{mg} / \mathrm{kg}$ and to rats by gavage at doses of 25,75 , and $250 \mathrm{mg} / \mathrm{kg}$ for human dose $\left(800 \mathrm{mg} / \mathrm{day}\right.$ ) on a mg/m $\mathrm{m}^{2}$ basis (imice) or $0.3,0.9$, and 3.0 times th
maximumm human cose on a maj/m

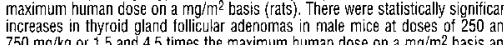
in male rats at a dose of $250 \mathrm{mg} / \mathrm{kg}$ or 3.0 times the maximum numan dose on a mo/m² basis. Mammary gland adenocarcinomas were statistically significantly 3.0 times the maximum recommented human dose on a mg/me basisi). Thyroid
follicular cell adenomas may have resulted trom chronic stimulatation of the thyroid follicular cell adenomas may have resulted rom conronic stimulation of the thynod
glard by thyroid stimulating hormore (TSH) resulling frem enhanced metabolis
and and clearrance of thyrroxine by rodent liver. Changes in TSH, thyroxine, and thyroxin
clearance consistent with this mechanism werer observed in subchronic toxicity
studies in rat and mouse and in a 1 -year toxicity study in rat; howevere, the result't of these studies were not detinitive. The relevance of the increases in thy roid follicula
cell adenomas to human risk, through whatever mechanism, is cell acenomas to numan risk, through whatever mechanism, is unknown
Antipsychotic drugs have been shown to chronically elevate proiactin evelels in
rodents. Serum measurements in a 1-yr toxicity study stowed that quetiapin increased median serum prolactin levels a maximum of 32 - and 13 -folc in male an
female rats. respectively. Increases in mammary neoplasms have been found i female rats, respectively. Increases in mammary neoplasms have been found in
rodents after chronic administration of other antipsychotic drugs and are considered
to be prolactin-mediated. The relevance of this increased incidence of prolactinmediated mammary gland tumors in rats to human risk is unknown (see
Hyperprolactinemia in PRECAUTIONS, General). Mutagenesis. The mutagenic
potential of quetiap ine was tested in six in vitro bacterial gene mutation assays and

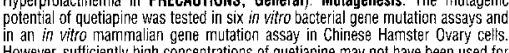
all tester strains. Quetiapirie did produce a reproducible inc rease in mutations in on evidence of clastogenic potential was obtained in an in vitto chromosomal aberration
assay in cultured human lymphocytes or in the in vivo micronucle eus assay in rats. Impairment of Ferti ility: Quetapine decreased mating and fertility in male Sprague-
Dawley rats at oral doses of 50 and 150 mg/kg or 0.6 and 1.8 times the maximum human dose on a mgg/m $m^{2}$ basis. Drugi-related effects included increases in interval
to mate and in the number of matings required tor successful impregnation. Thes ettects continued to be observed at $150 \mathrm{mg} / \mathrm{kg}$ even atter a two-week period without
treatment. The no-effect dose for impaired mating and tertility in mate rats was
$25 \mathrm{mg} / \mathrm{kg}$, or 0.3 times the maximum human dose on a mo $\mathrm{m}^{2}$ basis. Quletiadinie

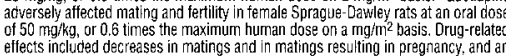
increase in the interval to mate. An increase in irregular estrus cycles was observed
at doses of 10 and $50 \mathrm{mg} / \mathrm{kg}$, or 0.1 and 0.6 times the maximum human dose on a at doses of 10 and $50 \mathrm{mg} / \mathrm{kg}$, or 0.1 and 0.6 times the maximum human dose on a
mygm² basis. The no-effect dose in female rits was 1 mg/kg. or 0.01 times the

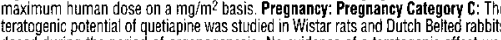
dosed during the period of organogenesis. No evidence of a teratogenic effect was
detected in rats at doses of 25 to $200 \mathrm{mg} / \mathrm{kg}$ or 0.3 to 2.4 times the maximum
human dose on a maj $\mathrm{m}^{2}$ basis or in rabits at 25 to $100 \mathrm{mg} / \mathrm{kg}$ or 0.6 to 2.4 times the maximumn human dose on a mg/m² basis. There was, however, evidence

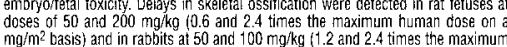

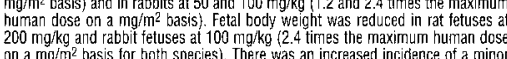

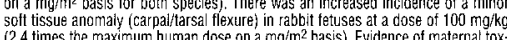
(2.4 times the maximum human dose on a mo/m2 basis). Evidence of maternal tox-
icity (i.e., decreases in body weight gain and dor death) was observed at the high dose in the rat study and at all doses in the rabbit study. In a peril postnatail repro-
ductive study in rats, no drug-related effects were observed at doses of 1,10 , and

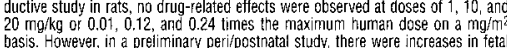

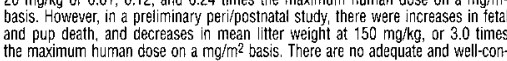
the maximum human cose on a mg/ $\mathrm{m}^{2}$ basis. There are no adequate and well-col
trolled studies in pregnant women and quetiapine should be used during pregnanc only if the potential benefit justifies the potential risk to the fetus. Labor an
De livery: The effect of SEROQUEL on labor and delivery in humans is unknown.
SEROQUEL ("in (quetiapine fumarate) Tablets

Nursing Mothers: SEROQUEL was excreted in milk of treated animals during lacta-
ion. It is not knOWn if SEROOUEL is excreted in hiluminan milk. II is recommengded that women receiving SEROQUEL should not breast feed. Pediatric Use: The satety and werer 65 years of age or over. II g general, there was no ind Sation of and yifferent

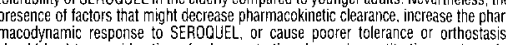
should lead to consideration of a lower starting dose, slower titration, and carefu monitoring during the initial dosing period in the elderly. The mean plasma clearance younger patients.
ADERESE REACTIONS

Adverse Events Oceurring at an Incidence of $1 \%$ or More Among SEROQuEL Ireated Patients in Short-Term, Placebo-Controlled Irials: The most commonly
observed adyerse events associated with the use of SEROQUEL (inciderice of $5 \%$ or

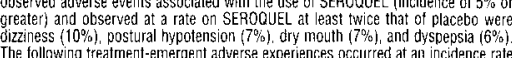

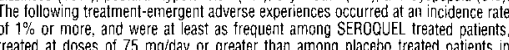

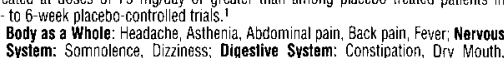

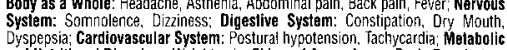
and Nutritional Disorders: Weight gain; Skin and Appendages: Rash; Respiratory
System: Rhinitis;: Special Senses: Ear pain

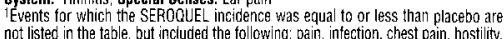

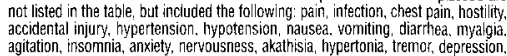

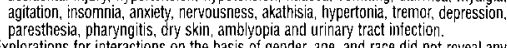
Explorations for interactions on the basis of gender, age, and race did not reveal any

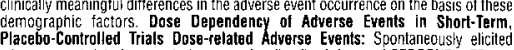

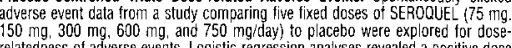
re atedness of adverse events. Logistic regression analysses revealed a positive dose
response (p<0.05) for the followowing adverse events': dyspepsia. abdominal pain, and

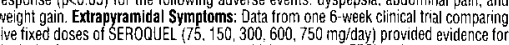

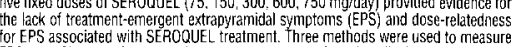
EPS: (1) Simpson-Angus total score (mean change from baseline) which evaluates
parkinsonism and akathisia, (2) incidence of spontannous complaints of EPS
(akathisisa, akinesia, cogwheel rigiditity. extrapyyramidal synnorome, hypertonia, hypoki(akathisia, akinesia, cogwhee rigiditity, extrapyramidal syndrome, hypertonia, hypokk-
nesia, neck rigiditity, and tremor), and (3) use of antiticholinergic medications to treat emergent EPS. In three additional placebo-controlled clinical trials using variable
doses of SEROCUUEL, there were no differencens betwetent the SEROQUEL and placebo

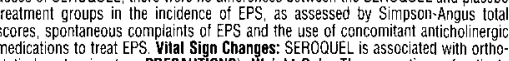

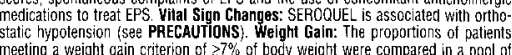
meeting a weight gain criterion of $7 \% \%$ of bocy weight were compared in a pool o
tour 3 - to 6 -week placebo-controled clinical trials, revealing a statistically significantly

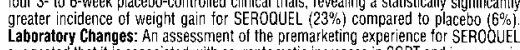
suggested that it is associater with asymptomatic increases in SGPT and increases in tological parameters in short-term, pacebo-controlled trials revealed no cilinically
important differences between SEROQUEL and placebo. ECG Changes: Between

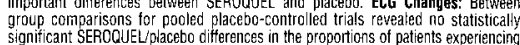
potentially important changes in ECG parameters, including QT. QTC, and PR intervals
However, the proportions of oatients meeting the criteria tor tachycard a were compared

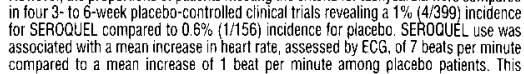
compared to a mean increase of 1 teat per minute among placebo patients. This
slight tendency to tachycardia may be related to SEROCuEL's potential for inducino
orthostatic changes isee PRECAUTTIONS). Other Adverse Events Observed During the Pre-Marketing Evaluation of SEROQUEL: Folloving is a list of COSIART teims that reflect treatment-emergent adverse eventits as definned in the introduction to the
ADVERSE REACTIONS section reported by patients treated with SEROOUE at multiple

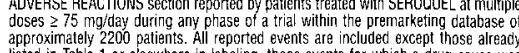
remote and those event terms which were so gvents for which a drug cause was

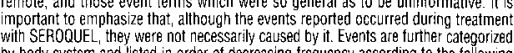
by body system and isted in order of decreasing frequency according to the following
definitifons : frequent adverse events are those occurring in at least $1 / 700$ patients appear in this listing); intrequent adverse events are those occurring in $1 / 700$ to 171000 patients; rare events are those occurring in tewer than 11000 patients.
Nervous system: Frequent: hypertonia, dysarthria: infrequent: abnormal drearns. dyskinesia, thinking abnormal, tardive dyskinesia, vertigo. involuntary movements,
contiusion, amnasia, psychosis, hallucinations, hyperkinesia libido increased ", urinary retention, incoordination, paranoid reaction, abnormal gait, myoclonus, delusions,
manic reacticn, apathy, ataxia, depersonalization. stupor, bruxistrm, catatonic reaction, hemiplegia; Rare: aphasia, buccoglossal syndrome, choreoathetcsis, delirium, emo-
tional lability, euohoria, libido decreased tional lability, euphoria, libido decreased ${ }^{*}$, neuralgia, stuttering, subcural hematoma
Body as a Whole: Frequent; flu syndrome; infrequant: neck pain, pelvic pain", suicide attempt. malaise, photosensitivity reaction, chills, face edema, moniliasis, Aars: salivation, increased appetite, ganmma glutarny! transpeptidase increased, gingivitis,
dysphagia, flatulence, gastroenteritis, gastritis, hemorrhoids, stomat itis, thirst, tooth

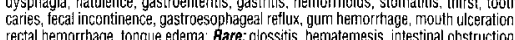
melena, pancreatitis. Cardiovascuiar system: Frequent: palpitation, Infrequent;
vasodilatation, $Q T$ i interval prolonged, migraine, bradycardia, cerebral ischemia,
irregular pulse. TTave abnormality, bundie branch biock, cerebrovascular accident.

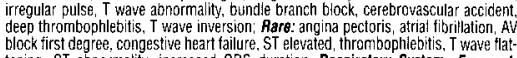
block first degree, congestive heart tailure. ST elevated, thrombophiebits, T wave tlat-
tening. ST abnormality, increased GRS duration. Respiratory Sysiem: Frequent:

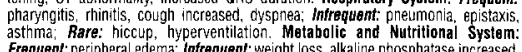

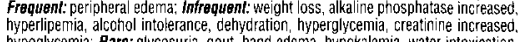

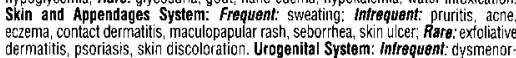

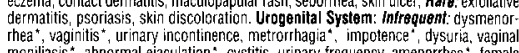

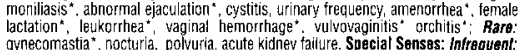
gynecomastia*, nocturia, polyuria, acute kidney tailure. Special Senses: Infrequent
conjunctivitis, abnormal vision, dry eyes, tinnitus, taste perversion, blepharitis, eye pain; Rare: abnormality of accommocation, deatness, giaucoma. Musculoskeletal leg cramps, bune pain. Hemic and Lymphatic System: Frequent: leukopenia;
Intrequents leukocytosis, anemia. ecchymosis, essinophilia, hypochromic anemia:

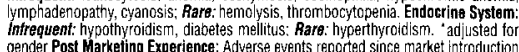
gender Post Marketing Experience: Adverse events reported since market introduction which were temporaly related ta SEROQUEL therapy include the following: rarely
leukopenianneutropenia. If a patient developS a low white celli count consider dispre-existing of low white cell coont and history of drug ind iced leukopentia/neutropenia.
DRUG ABUSE AND DEPENDENCE Controlled Substance Class: SEROQUEL is not a controlled substance. 


\section{Editorial Questionnaire}

Your comments are important to us. This torm provides you with the opportunity to express your opinions. Our goal is to make CNS Spectrums your source for practical and clinical neuropsychiatric information. By filling out this Questionnaire, you enable us to incorporate your views about our editorial content in future issues. Please fill out this form in its entirety. Thank you.

Name (please print)

Address

City

State

Zip Code

E-mail

Specialty

Signature

Date

Fax this form to 212-328-0600. Or mail it to: CNS SPECTRUMS, MBL Communications, Inc., 333 Hudson Street, 7th Floor, New York, NY 10013

1. On a scale of 1 to 5 (1=Poor, $5=$ Excellent), please indicate your level of interest and/or satisfaction with the editorial content in this issue.

Original Research and Review Articles

Migraines: Neurological and Psychiatric Perspectives
$\square 1$
$\square 2$
$\square 3$
$\square 4 \quad \square 5$

Departments

Clinical Updates in Neurology
$\square 1$
$\square 2$
$\square 3$

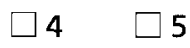

Clinical Updates in Psychiatry

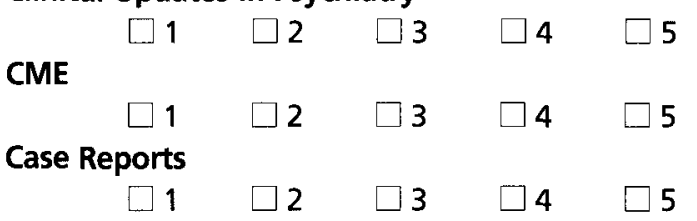

The Neurology of Behavior

$\square 1 \quad \square 2 \quad \square 3 \quad \square 4 \quad \square 5$

2. Which areas of neuropsychiatry would you like us to cover in the future?
3. Please describe your reading pattern for this issue:

$\square$ Read cover to cover
$\square$ Skimmed table of contents
$\square$ Read select items of interest
$\square$ Skimmed text
$\square$ Did not read

4. On a scale of 1 to 5 ( $1=$ Incomplete, $5=$ Comprehensive), how would you describe the depth of coverage for this issue?
$\square 1$
$\square 2$
$\square 3$
$\square 4 \square 5$

5. Any other comments about CNS Spectrums' editorial content, design, or overall usefulness?

6. Please indicate your title:

$\square$ Psychiatrist

Please select any of the following educational materials you would like to receive:

\section{CME Accredited CNS Roundtable Monographs and CD-ROMs \\ $\square$ Pharmacologic Advances in the Treatment of ADHD \\ $\square$ The Use of Lithium in Bipolar Disorder \\ $\square$ Atypical Antipsychotics in the Treatment of Bipolar Disorder \\ $\square$ Recognizing Comorbidities Associated With ADHD \\ $\square$ Remission-Oriented Treatment Considerations of Bipolar Disorder}

\section{Clinical Pocket Reference Guides}

$\square$ The 2003 Black Book of Psychotropic Dosing and Monitoring

$\square$ The Diagnostic and Therapeutic Guide to Sleep Disorders

$\square$ The Effects of Antidepressants on Human Sexuality

$\square$ Dosing and Monitoring Guidelines: Mood Disorders

$\square$ The Side-Effect Profiles of Antipsychotic Medications 


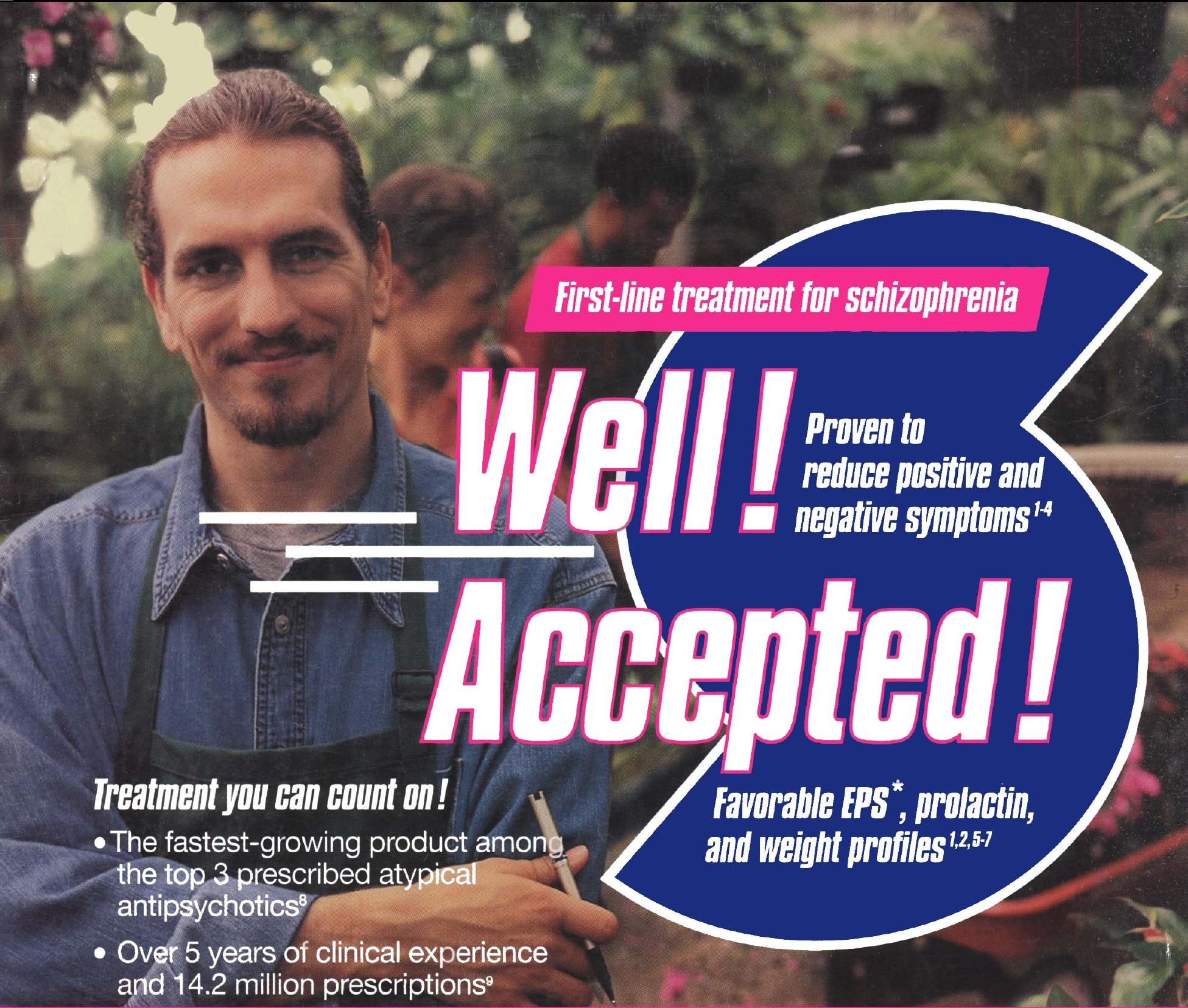

The most common adverse events associated with the use of SEROQUEL are dizziness $(10 \%)$, postural hypotension $(7 \%)$, dry mouth $(7 \%)$, and dyspepsia $(6 \%)$. The majority of adverse events are mild or moderate. In $3-$ to 6 -week, placebo-controlled trials, the incidence of somnolence was $18 \%$ with SEROQUEL vs $11 \%$ with placebo.

As with all antipsychotic medications, prescribing should be consistent with the need to minimize the risk of tardive dyskinesia, seizures, and orthostatic hypotension.

As with all antipsychotic medications, a rare condition referred to as neuroleptic malignant syndrome (NMS) has been reported.

*Extrapyramidal symploms.

Reterences: 1. Smatl JG, Hirsch SR, Arvanitis LA, et al, and the SEROQUEL Study Group. Quetiapine in patients with schizophrenia: a high-and low-dose double-blind comparison with placebo. Arch Gen Psychiatry. 1997:54:549-557. 2 Arvanitis LA, Milter BG, and the SEROQUEI Trial 13 Study Group. Multiple fixed doses of "Seroquel" (quetiapine) in patients with acute 1997:42:233-246. 3. Borison RL, Arvanitis LA, Miller BG and the U.S. SEROQUEL Study Group. ICl 204,636, an atypical antipsychotic: efficacy and safety in a multicenter, placebo-controlled trial in patients with schizophrenia. J Clin Psychoohamacol. 1996;16:158-169. 4. Data on file, Study S91. Astrazeneca Pharmaceuticals LP. Wilmington, Delaware. 5. SEROQUEL" (quetiapine fumarate) Prescribing Information, Rev 1/01, AstraZeneca Pharmaceuticals LP. Wimington. Delaware. 6. Brecher M, Rak IW, Metvin K, et at. The long-term effect of quetiapine (Seroquel") monotherapy on weight in patients with schizophrenia. Int J Psych Clin Pract. 2000:4:287-291. 7. Data on file. DA-SER-02. Astra7eneca Pharmaceuticals LP Wilmington,

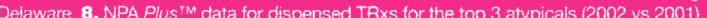
Atypical Market. IMS Amenica. Ltd., 2002. 9. Data on file. DA-SER-10. AstraZeneca Pharmaceuticals LP, Wilmington, Delaware.
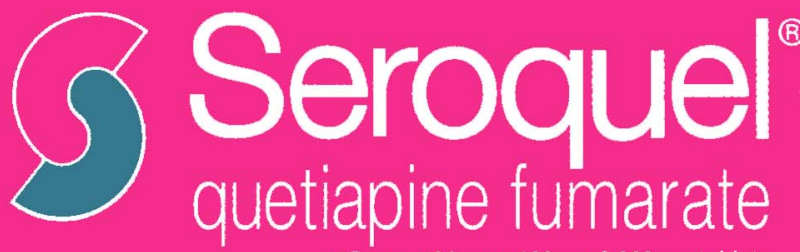

$25 \mathrm{mg}, 100 \mathrm{mg}, 200 \mathrm{mg} \& 300 \mathrm{mg}$ tablets

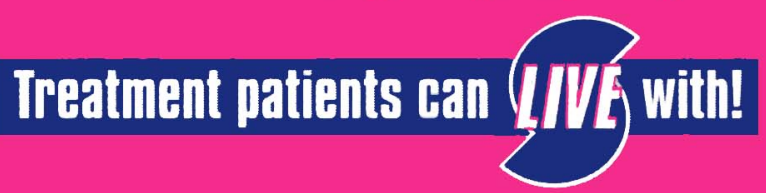

AstraZeneca Pharmaceuticals LF $2107323 / 03$
(1) 2003 AstraZeneca Pharmaceuticals LP. All rights reserved. SEROQUEL is a registered trademark of the AstraZeneca group of companies. Please see Brief Summary of Prescribing Information on following page. 